\title{
PLOTINO - O RETORNO AO UNO
}

\author{
Reinholdo Aloysio Ullmann*
}

\begin{abstract}
SINTESE - Neste artigo, o autor aborda o retorno da alma ao Uno, de acordo com a doutrina plotiniana. Para tanto, é mister a dialética, entendida como abstração (renúncia) das coisas materiais e das paixões. A inteligência, a vontade e as virtudes devem colaborar, para alcançar o objetivo último da vida: a união mistica com o Uno. $\mathrm{O}$ artigo alude, também, à metempsicose defendida por Plotino. No fim, são recordados alguns aspectos da influência exercida por Plotino sobre a Idade Média e o pensamento filosófico posterior.
\end{abstract}

\begin{abstract}
This paper deals with the return, proposed by Plotinus, of the human soul to the One (God), by means of dialectics, i. e., giving up the surrouding world and passions. The human intelligence and will, as well as civic and cathartic virtues, must collaborate in order to attain, already during this earthly life - and it's possible - the aim of the soul: the mystical unity with God. The author alludes also to the metempsychosis defended by Plotinus. Among other viewpoints Plotinus influence on the Middle Ages and on later times is here shown.
\end{abstract}

Examinaremos, neste trabalho, o retorno da alma humana ao Uno, princípio sem princípio de todas as coisas.

A relação do esquema cósmico de Plotino com ânsia de salvação funda-se em que, pela descrição metódica das hipóstases do ser, torna-se manifesta à alma a necessidade de retornar à pátria perdida. Para percorrer o caminho de regresso ao Uno, que em Plotino equivale a Deus, é mister à alma fazer abstração do mundo sensivel (Entweltlichung, aphairesis).

Do mesmo modo como uma criança, separada da família, desde a infância, desconhece os seus pais, há homens que não possuem conhecimento de Deus, ${ }^{1}$ porque imergem na matéria e se dispersam no múltiplo, julgando ser tal a vida verdadeira, quando de fato não $o$ é$^{2}$

\footnotetext{
* Professor da Pontifícia Universidade Católica do Rio Grande do Sul, PUCRS, e da Universidade do Vale do Rio dos Sinos, UNISINOS.

1 Enéadas, V, 1, 1.

2 "Im Blick auf uns selbst können wir klar erkennen, dass das Trachten nach dem Hier und Dort, dem Anderen und wieder Anderen auf einer Verkennung beruht. Solches Hinausgehen in das Aussereinander des Hier und Dort scheint nur das umfassendere, reichere Leben zu sein. In Wahrheit ist dieses Leben im sich zerstreuenden Sichvergeben an das Aussereinander ein fortgesetzter Selbst - und Seinsverlust" (VOLKMANN-SCHLUCK, Karl-Heinz. Plotin als Interpret der Ontologie Platos. Dritte erweiterte Auflage. Frankfurt am Main: Vittorio Klostermann, 1966, p. 150).
}

\begin{tabular}{|l|l|l|l|l|l|} 
VERITAS & Porto Alegre & v. 41 & $\mathrm{n}^{\mathrm{0}} 161$ & Março 1996 & p. 27-36 \\
\hline
\end{tabular}


Para Plotino, a vida só é desejável, quando tem o Bem por princípio e fim. ${ }^{3} \mathrm{O}$ Bem é o princípio absoluto, do qual depende todo o resto, por emanatismo. ${ }^{4}$ Absoluto, existente por si mesmo, anterior a todas as coisas, assim Plotino concebe 0 Uno. ${ }^{5}$

Na ordem dos entes, o bem, para cada um deles, acha-se no principio, que the é imediatamente superior. Assim, o bem da matéria é a forma; o bem do corpo é a alma; o bem da alma é a inteligência; o bem da inteligência é o Absoluto. Cada um desses bens produz algo no ser do qual é o bem: a forma dá à materia a ordem $e$ a beleza; a alma confere ao corpo a vida; a inteligência dá à alma a sabedoria e a felicidade; por fim, o Bem dá à inteligência a luz que ilumina. ${ }^{6}$

\section{1 - Condições necessárias para chegar ao Uno}

Epistrophé (volta para) é o termo usado por Plotino para designar o retorno da alma à sua origem. ${ }^{7}$

Dois caminhos convergentes, orientados pela dialética, ${ }^{8}$ propõe Plotino, para ascender ao Uno: um, atinente à inteligência; outro, respeitante à vontade. Ambos devern assumir a tarefa da purificação (via purgativa), mediante gradativo desprendimento da matéria, pela abstração, aphairesis ou Entweltlichung. Áphele pánta ${ }^{9}$ era a divisa plotiniana, a qual apresentava incessantemente aos discípulos como lema de vida. Para retornar ao Uno, dizia o filósofo pagão, basta o esforço pessoal, sem auxílio de fora, pois ele estava convicto de que o Uno, por estar presente em tudo e por estarem todas as coisas presentes nele (panenteísmo), era dispensável o que os cristãos denominam graça ou dom gratuito de Deus. ${ }^{10}$ Já nesta vida, o ho-

3 Enéadas, VI, 17, 20.

4 O emanatismo plotiniano é hoje interpretado como sinônimo de criação. "Plotinische Emanation und christliche Kreation stellen also keine Gegensätze dar. Gemeinsam ist beiden die Front gegen die Platonische Demiurgia und den Evolutionismus. Das Plotinische emanare besagt im Grund und Wesen nichts anderes als das christliche creare ex nihilo". (HISTORISCHES WÖRTERBUCH DER PHILOSOPHEE. Völlig neubearbeitete. Ausgabe. Basel/Stuttgart: Schwabe \& CO Verlag, 1972. Band 2 , col 446. Herausgegeben von Joachim RITTER).

5 PLOTINO concebe o Uno como Nada ou Nada de tudo. O que significa isto? "Egli Nulla di quello di cui è l'origine" (BEIERWALTES, Werner. "Pensare l'Uno". Milano: Vita e Pensiero, 1985, p. 125).

Enéadas, VI, 23 e 25.

7 "His great object is to show those few who are capable of comprehending his teaching the way to retum to their true origin, which is also their true end, the One or Good, the first principle or reality which is obtainible only in a union beyond thought or description, and which must be prepared for by the attainment of moral and intellectual perfection. The impulse to retum comes ultiinately from the One itself" (The Encyclopedia Americana. New York: Americana Corporation, 1962. v. 22, p. 251).

8 "Questo movimento del pensiero che astrae dalla molteplicità conduce verso l'unità, e viene inoltre caratterizzato anche come ascesa, a partire da Platone va inteso come dialettica" (BEIERWALTES, op. cit., p. 27). Assim, dialética e conversão (metánoia) são conversiveis. A dialética é condicionada pela purificaçäo ética.

9 Enéadas, V, 3, 17 (cf. também IV, 3, 32 e VI, 9, 31).

10 No entanto, Plotino reconhece que 'l'unione mistica avviene per forze diverse da quelle che uniscono il pensante al pensato" (Enéadas, VI, 9, 8). 
mem reto e desprendido de tudo pode, na mente de Plotino, unir-se misticamente ao Bem, ou seja, a Deus. ${ }^{11}$

1.1 - Qual o papel da inteligência? Por ela, a alma capta a beleza em todas as suas formas, seja a beleza intelectual, interior, seja a beleza da arte ou do mundo circundante. $O$ belo tem o condão de fazer a alma entrar em si mesma e fazê-la recordar a origem divina. ${ }^{12}$ Mero belo de empréstimo, o belo sensivel constitui uma força motriz capaz de conduzir a alma ao belo incorpóreo. Para Plotino, o belo não anuncia ou enuncia simplesmente a si mesmo, mas é revelação de algo que o transcende, de algo inteligível. A beleza tem, pois, função iniciática. Ao Uno, Belo subsistente, a alma só logra alçar-se, se não mais tiver nenhuma alteridade, ${ }^{13}$ isto é, quando tiver abstraído, por completo, da matéria. Por outras palavras, o homem deve fugir do mundo. Essas palavras soam como se foram de um cristão, com os olhos e o coração voltados exclusivamente para o alto. Essa fuga do mundo Plotino expressa-a metaforicamente com o retorno de Ulisses à pátria. ${ }^{14}$

Tendo atingido a Beleza absoluta, a alma abandona todas as outras belezas, como um visitante de um palácio que deixa de olhar as estátuas do vestíbulo, ao encontrar-se com o dono da mansão. Por outra, a realidade deste mundo, com suas belezas, deve mover o homem para o mundo verdadeiro. ${ }^{15}$

Dissemos que Plotino pregava a fuga do mundo. Não se pense, no entanto, que isso significava desinteresse pela realidade social. Basta recordar que ele mesmo tinha sob seus cuidados a guarda de órfãos. Não se trata, pois, de uma fuga de desprezo radical, para viver num solipsismo, como estilita egocêntrico. Lembre-se o convívio com as altas autoridades em Roma e a solicitude paternal por orientar as consciências dos seus discípulos. Não se esqueça, também, a intenção de Plotino de fundar a Platonópolis. ${ }^{16}$

11 A união mistica com Deus é um evento mundano, que não necessita de condições anormais para verificar-se. Plotino adverte que se requer, para tanto, uma contemplação contínua e que a alma não seja afetada por nenhuma perturbação corpórea (cf. Enéadas, VI, 9, 10).

12 Cf. Enéadas, I, 6, 4.

13 Cf. Enéadas, VI, 9, 8.

14 Cf. Míada. I, 6, 8, 16s. No Teeteto, 176 a-b, Platão escreve: "É preciso elevar-se deste mundo para o alto, o mais rapidamente possivel. A fuga de que falamos não é outra coisa do que uma assimilação da natureza divina, quanto nos é possivel; assimilação, sobretudo, se se alcança a justiça e a santidade, com o exercício da inteligência".

15 "(...) ammirare nella bellezza che appare il creatore non vuol dire restare attaccati a ciò che appare come tale e lasciarsi affascinare solo da esso; lo implica piuttosto la domanda sul perchè di questa Bellezza. Tuttavia, il pensiero interrogante deve 'passare da questo a Quello'..." (BEIERWALTES, op. cit., p. 89).

16 Em nosso entender, Plotino jamais foi contrário à participação dos cidadãos na política. Por essa razão, data venia, não parece correto o que escreveu Max Pohlenz: "Auch von Platos Polisgefühl hat er nichts mehr. Er widerrät die politische Tätigkeit, und die Platonopolis, die er unter der Schirmherrschaft des Kaisers Gallienus in Campanien gründen wollte, wäre kein platonischer Idealstaat geworden, aber auch keine Akademie zur Heranbildung staatlicher Führerpersönlichkeiten, sondem eine Lebens - und Studiengemeinschaft weltabgewandter Gelehrter" (Die Stoa - Geschichte einer geistigen Bewegung. 6. Auflage. Göttingen: Vandenhoeck \& Ruprecht, 1984 p. 396). 
O mundo é belo e bom, ${ }^{17}$ ordenado e harmonioso. Com essa perspectiva, Plotino assumiu posição contrária aos gnósticos, os quais "todos têm um conceito pessimista da matéria, que consideram como essencialmente má e fonte do mal". ${ }^{18}$ Aliás são numerosos os verbos enumerados por Plotino, para mostrar como os gnósticos manifestavam o seu desprezo pelo mundo. ${ }^{19}$

Segundo Plotino, o mundo deve ser tomado como aquilo que é a partir do seu arquétipo: como início e impulso para chegar ao seu fundamento pela anagogê (ascensão) da alma purificada. Do começo ao fim, as Enéadas revelam uma nostalgia do divino, uma elevada sensibilidade religiosa.

1.2 - Visto em largos traços o papel da inteligência, vejamos o que incumbe à vontade. A ela cabe orientar-se, sem desvios, rumo ao Uno, a fim de com ele unirse em êxtase. Para tanto, é mister praticar as virtudes e valorizar a erótica. Nas virtudes, Plotino distingue as cívicas e as catárticas. As primeiras - justiça, prudência, fortaleza e temperança - não representam um ponto de chegada, mas um ponto de partida, porque traçam os limites aos desejos e moderam as paixões. Elas são apenas condição para assemelhar-se a Deus. ${ }^{20}$ Já as virtudes catárticas miram mais alto, porquanto liberam o homem das coisas sensiveis. Quais são essas virtudes? As mesmas que as cívicas, mas com função mais profunda. Com efeito, nesse estágio, o Nous, segunda hipóstase, torna-se modelo de virtude. (Note-se, entretanto, que o Nous não representa o ponto terminal da ascensão ao Uno). Assim, nesse nível superior da virtude, a sabedoria contacta com o Espírito; a justiça é o volver-se da alma ao Espirito; a temperança é a adesão íntima da alma ao Espirito; a fortaleza é a perseverança impassivel da alma no Espírito, sem paixão alguma no corpo. ${ }^{21}$ Sem dar importância ao corpo, ${ }^{22}$ como Heráclito, ${ }^{23}$ e desprendido das coisas sensiveis, o homem atinge a apátheia. ${ }^{24}$ Esse termo significa imperturbabilidade, tanto na saúde quanto na doença. A primeira, para Plotino, nada acrescenta à felicidade; a segunda em nada a diminui. ${ }^{25}$ Aqui Plotino valeu-se da

17 "Il mondo, certo, a causa del necessario legame che in esso logos o psyché ha con la Materia, non è senza limite e negatività, ma non è nemmeno il prodotto da intendere solo negativamente di una 'caduta' in senso gnostico; considerato a partire dall'essere dialettico dell'immagine, esso piuttosto, come immagine, la piu bella: grazie al suo essere-immagine riferita alla sua origine è il megliore di tutti i mondi" (BEIERWALTES, op. cit., p. 87).

FRAIIE/URDANOZ. Historia de la Filosofia. 4 ed. Madrid: BAC, 1986. v. II ( I ), p. 89.

9 Nas Enéadas, II, 9, por exemplo, Plotino arrola os seguintes verbos: ou timãn (= não respeitar o mundo); mémphestahi (= queixar-se de); aitiásthai (acusar, culpar, ter como causa de); pségein (= censurar, repreender); kataphronein (= menosprezar); asebein (= desrespeitar), misein (= odiar); loidoreisthai (= injuriar, insultar).

Enéadas, I, 2, 6.

Cf. REALE, Giovanni. "Storia della Filosofia antica". Milano: Vita e Pensiero, 1992. v. IV, p. 594.

Enéadas, I, 2.

23 PLOTINO refere-se ao efésio, citando o fragmento $n^{0} 96$.

24 "Die Apathie gehört also für Plotin zum Wesen der Seele als ihr ursprünglicher Besitz; sie behält aber für ihn auch ihren Sinn als sittliche Aufgabe, als die Forderung, den Affektionen des Leibes keinerlei Einfluss auf Vorstellung und Urteil zu verstatten, damit unser wahres Ich rein und unbefleckt erhalten wird. Im Erdendasein erreichen dieses Ziel nur wenige, und in absolutem Sinne wird die Apathie erst verwirklicht, wenn die Seele nach der völligen Trennung vom Leibe wieder ausschliesslich im Reich des Immateriellen weilt" (POHLENZ, op cit., p. 396).

Enéadas, IV, 14, 20-30. 
filosofia estóica, mas ultrapassou a indiferença por ela pregada, pois ele chega a desejar a dor.

Mediante tal ascese e prática ética, Plotino desejava melhorar e mudar o mundo e a concepção estóica ainda reinante cá e lá. ${ }^{26}$ Julgava loucura abandonar 0 mundo pelo suicídio. ${ }^{27}$ Para os estóicos, o suicídio constituía um ato moralmente bom e até heróico. Plotino, ao contrário, afirmava que, mesmo em meio ao sofrimento, é possivel ser feliz. ${ }^{28}$ Em suma, "a virtude consiste em voltar-se para dentro de si e olhar-se a si próprio". ${ }^{29}$

1.3 - Vinculada à via purgativa e conducente à via iluminativa e unitiva está a erótica, que sinonimiza com atração amorosa, por parte do Uno, como Beleza. O Uno, kalón em si, é, ao mesmo tempo, alguém que chama - kalein, em grego. Pela erótica, a alma transcende o belo corpóreo, com função iniciática, e se eleva ao Belo em si. Quem se apega ao belo corpóreo ou ao corpo belo, para possui-lo e perpetuar a espécie (pelo sexo), é semelhante a Narciso, que encontrou a morte na contemplação da beleza efêmera. ${ }^{30} \mathrm{O}$ amor das formas é simples condição onginária, que deve ser des-velada, compreendida pela inteligência e transfigurada pelo eu interior. "O eros da alma superior é um deus que a une eternamente ao Bem". ${ }^{31}$

1.4 - Todos os homens, em principio, têm condições para guindar-se à contemplação do Bem e à união mais íntima possível com ele. Nem todos, porém, atingem essa meta nesta vida, porque ficam imersos na matéria e se perdem na multiplicidade. ${ }^{32}$ Tais homens ignoram o que seja a vida verdadeira da virtude, da renúncia, do áphele pánta.

Em oposição a eles, Plotino arrola três classes de homens, que podem mais facilmente alcançar a contemplação das coisas eternas e do Uno: os músicos, os amantes e os filósofos. Vejamos a razão dessa afirmativa plotiniana.

O músico encanta-se com o belo da harmonia dos sons e tons os quais resultam em ritmo que embala o espírito. Em lugar de ficar preso à materialidade dos sons, o músico deve convencer-se de que a beleza musical repousa, em seu fundamento, numa harmonia inteligível, a qual constitui o Belo em si. Por outras palavras, a harmonia dos sons é uma representação invisível, transcendente. Os sons

26 Como bom grego, Plotino jamais perdeu de vista que todas as coisas dependem da perfeição absoluta e que tudo forma uma unidade. Dentro dessa perspectiva, é mister colocar a sua moral. "Estimant que l'univers tend à un but, elle (la philosophie) a pensé que l'homme, lui aussi tend à ce but, et que cette tendance le met d'accord avec l'ensemble des choses. Ainsi la voie était ouverte à la morale. Car la morale a son fondement dans la métaphysique: le privilège, en métaphysique, de la philosophie grecque, s'est accompagné d'un égal privilège en morale" (WERNER, Charles. La philosophie grecque. Paris: Payot, 1946, p. 281).

27 Enéadas, I, 9.

28 'Essere felice anche fra i tormenti, nel 'toro di Falaride', è, sì, possibile, perché è possibile, anche fra i tormenti fisici unirsi con l'anima incorporea al Divino incorporeo..." (REALE, op. cit., p. 591). A condição, para ser feliz no sofrimento, é que não se perca de vista o Bem, em sua plenitude (Enéadas, 1, 4, 13). Enéadas, III, 5, 4. "Das Mitsichgeeintsein ist etwas Gutes, das Vielessein etwas Schlechtes" (VOLKMAN-SCHLUCK, op. cit., p. 150). 
materiais mediatizam a beleza simplesmente e convidam para escutar a harmonia do alto. ${ }^{33}$

Se o músico é movido pelos sons, o amante é movido pelo amor (éros). Este, inicialmente, deriva dum ato da visão (éros provém de hórasis), ministrando uma experiência sensivel do belo. A partir dali, é fácil elevar-se ao belo não material, no qual se incluem as leis justas, os costumes probos, o conhecimento intelectual, as virtudes. Envolto por essa atmosfera, o amante tem as condições para entrar em contato com a Super-Beleza - o hiperkalón.

A terceira classe de homens, com posição privilegiada para a contemplação e união com o Uno, é a dos filósofos, porque o filósofo já saiu da caverna e já se encontra no mundo da contemplação. ${ }^{34}$

Esses exercícios dialéticos têm a função de elevar o homem ao reino do puramente espiritual, ao princípio sem princípio.

O retorno da alma ao seu fundamento último - o Uno - é, para Plotino, tão natural como o é a emanação dele. Por isso, não necessita de nenhum dom gratuito ou graça superinfusa, nem de uma intervenção extranatural. O regresso é constitutivo da própria essência do Uno. Isso traz implicações de ordem escatológica, segundo veremos a seguir.

\section{2 - A união mística com o Uno}

2.1 - A culminância da dialética plotiniana é a união mística com o Uno, numa contemplação extática. Hénosis é a palavra grega para designar essa união. No caminho da "conversão", que caracteriza o itinerário da "inteligência espiritual" no homem, Plotino aponta para além da intelecção, para a pura intuição do Uno, que é simples e sem alteridade. Aqui, a alma prescinde de toda razão discursiva e de toda ciência. Trata-se de um estado hiper-racional que tem como um dos momentos preparatórios a reflexão, a virtude, a ascese.

2.2 - O que significa união mística? Uma co-presença com o divino, atemporal em que a alma entra na posse e unidade máxima de si mesma, para alcançar a similitude com o Uno (homoiôsis tô Theô).

Mística deriva do verbo grego mýô e significa fechar-se; especialmente fechar os olhos, recolher-se. Por isso, mystikón é o oposto de phanerón (aberto, manifesto). Em Plotino, a mística é pensada como háplôsis, isto é, como máxima simplificação da alma racional, quando ela se retrai para o fundamento do seu ser. ${ }^{35}$ Para que se dê tal união, misteriosa, secreta, indizivel com o Uno, é mister deixar atrás de si a matéria. Não se trata, pois, na mística, de um sonho de visionário, nem é

33 Enéadas, I, 6, 3. Talvez aqui Plotino se tenha inspirado em Heráclito, fr. 54: "A harmonia não manifesta é mais forte do que a (harmonia) manifesta".

Enéadas, I, $3,3$.

"(...) háplôsis; das ist: höchste Vereinfachung der vernunfthaften Seele, wenn sie sich auf ihren mit dem Ureinen wesengleichen Grund zurückzieht. Auch dabei fällt allerdings das Bewusstsein aus, wie in den orgiastischen Verzückungen, jedoch um eines vermeintlich noch höheren Lichts willen und nicht um in Krämpfen, Nebel, Blutschein zu stranden. Plotin und der Neuplatonismus sind so der Ursprung, ja Inhalt aller späteren christlichen Mystik, weder Dyonisios Areopagita noch Meister Eckardt haben Neues zugefügt" (BLOCH, Emst, Atheismus im Christentum. Frankfurt am Main: Suhrkamp Verlag, 1968, p. 93). 
identificável com transes xamânicos ou com o enthousiasmós dos órficos e dos participantes dos ritos dionisíacos. A mística plotiniana não é deificação, mas assemelhação com Deus.

Na vivência da união mística, a alma entra, por assim dizer, no Santo dos Santos, que representa o abandono das imagens (as estátuas dos deuses) as quais simbolizam o singular ou o muito. ${ }^{36}$ Aqui a alma repousa como Deus, no sétimo dia. Muitas vezes, também os místicos descrevem a sua união com Deus como a entrada num deserto. Deserto, aqui, não significa lugar vazio, mas é uma analogia para representar a solidão da alma com o Uno. Tudo a alma abandonou (deserere, em Latim), para defrontar-se com a dimensão divina. Então, a alma está despojada de tudo. Cumpriu o áphele pánta. É o instante da contemplação, com plena felicidade, ${ }^{37}$ numa vivência supra-sensivel, trans-racional, atemporal. É descanso no Uno. ${ }^{38}$ Ekstasis equivale ao excessus mentis dos medievais, ao arrebatamento (rapto) de Paulo, descrito em 2Cor 12, I. Somente o puro pode contemplar o Puro.

Não se pense, porém, que o êxtase seja dissolução do eu. Não é anulação, nem deificação, mas assemelhação com Deus. ${ }^{39}$

2.3 - A par dessa visão grandiosa do destino da alma humana, encontramos um paradoxo: Plotino nega a ressurreição da carne (o que dá a entender que dela tinha ouvido falar de amigos cristãos). Diz o filósofo: "Ressurgir com um corpo equivale a cair dum sono em outro; a passar, por assim dizer, de um leito a outro". ${ }^{40}$

2.4 - E o que acontece com os homens que não chegam, na primeira existência, ao cume da perfeição, ou seja, à união com o Uno pelo êxtase? Seu destino é a metempsicose. Aqui Plotino revela-se inteiramente platônico. A metempsicose, ou melhor, a metensomatose traz a possibilidade de reencarnar-se em corpos de animais e até de plantas, consoante a vida levada na existência precedente. ${ }^{41}$

2.5 - Qual será o destino dessas almas, ao fim de suas transmigrações? A apocatástase. ${ }^{42}$ Dado o caráter naturalístico da emanação, não pode haver diversidade de destinos. Todas as almas devem retornar ao Uno. ${ }^{43}$ Porém, assim como, pela

36

37

38

40

41

42

43

Cf. BEIERWALTES, op. cit., p. 346, nota 59.

Enéadas, VI, 7, 31.

"Ek-stasis nell'unificazione diventa stasis del pensiero; in esso Eros, come stabile impulso al movimento che trascende, è giunto al suo fine definitivo e perciò alla 'quiete' in uno 'stato' del non-essere-più-mosso, dell'essere orientato fissamente all'Uno o dell'unione (synousía) senza distanza con lui" (BEIERWALTES, op. cit., p. 131).

39 "In der Ekstase bringt sie (die Seele) sich in das als ein jenseits ihrer selbst begegnend überweltliche Selbst" (VOLKMANN-SCHLUCK, op. cit., p. 9). "There (in the mystical union) is no consciousness of duality in that union; we are not aware of ourselves; but we are not destroyed or dissolved into the One, because even in the union we are still intellect 'out of itself', transcending its normal nature and activity" (Encyclopaedia Britannica. Chicago: 1969, v. 18, p. 60).

Enéadas, III, 6, 6.

Cf. REALE, op. cit., p. 590.

Apokatástasis, em grego, significa "posto primitivo, restauração, regeneração", também quer dizer "devolver a saúde a alguém". Na linguagem teológica, tem o sentido de eliminar a diferença entre salvos e condenados. Ao fim e ao cabo, bons e maus se salvarão. Essa doutrina foi proposta por Ońgenes e condenada pela Igreja (cf. DENZINGER/SCHÖNMETZER, $n^{\circ} 411$ ).

Cf.ENCICLOPEDIA FILOSOFICA. Venezia/Roma: Istituto per la Collaborazione Culturale, 1957. v. I, col. 1863. 
emanação, o Uno não sofre diminuição, ${ }^{44}$ porque não despotencializa a sua substância, assim também, pelo retorno das almas, não recebe acréscimo, ${ }^{45} \circ$ que exclui, por conseguinte, toda e qualquer interpretação panteística. O Uno é transcendente e imanente.

2.6 - Cabe perguntar aqui: se alguém, como Plotino, teve o privilégio do êxtase, já neste mundo, que influência exerce isso sobre a vida cotidiana? Responde Plotino: verá transfigurada a realidade física e humana, viverá o eterno no devir temporal e amará em Deus todas as coisas, com amor sereno. Dessa intuição excepcional nascerão as grandes ações que orientam eticamente a Humanidade; surgirá renovação religiosa e atividade dos políticos sábios, com um senso cada vez maior de solidariedade social. ${ }^{46} \mathrm{Tal}$ homem não permanecerá num quietismo inoperante, mas com alegria agirá desinteressadamente. ${ }^{47}$

Pelos frutos se conhece a árvore. Mensurada racionalmenle, a união mística é absurda e paradoxal porque o Uno se encontra para lá de toda predicabilidade e porque a contemplação mística representa uma experiência pessoal intransferivel e inefável. ${ }^{48}$ De outra parte, não se pode pôr em dúvida ou negar essa vivência de muitas almas a sós com Deus, nem considerá-la um sonho, paranóia ou anomalia, pois os efeitos da visão do Uno demonstram a convicção da realidade vivenciada.

Em nossa época de crasso materialismo, não admira que a mística religiosa seja olhada com certo desdém. "Na filosofia moderna, consuma-se a cisão entre filosofia e mística, com o desaparecimento do espaço noético da 'inteligencia espiritual'. À mística como experiência do Deus transcendente sucedem-se as místicas da imanência: da história, da revolução, do super-homem, da terra e, finalmente, do nada". ${ }^{49}$ Faltam ao homem de hoje as aures religiosae de que falava Cícero.

\section{3 - A fecundidade da mensagem plotiniana}

Concluimos este pequeno estudo com algumas achegas a respeito da fecundidade da mensagem plotiniana na História, com dúplice divisão: a primeira, atinente ao conceito de emanação; a segunda, relativa à mística.

3.1 - Visto não haver contradição entre o emanacionismo plotiniano e a criação em sentido cristão, ${ }^{50}$ não poucos pensadores cristãos valeram-se do conceito de emanacionismo, sinonimizando-o com criação. Vejamos alguns exemplos. Boécio insiste no fluir ou defluir das coisas livremente quisto por Deus. ${ }^{51}$ Também o

44 O Uno é perfeito desde toda a etemidade (Enéadas, III, 8, 11). Não sofre diminuição de sua substância, pela emanação (Enéadas, III, 8, 8); não precisa de nada (ou déxetai ti) (Enéadas, I, 6, 7).

45

46

47 Enéadas, V, I, 4, cf. etiam III, 8, 9 e V, 12, 40.

Enéadas, I, 5, 10; V, 8, 11; VI, 9, 7.

Enéadas, III, 2, 8; VI, 9, 7.

48 A hénosis (unificação) com o Uno só pode "ser sabida" por quem a viveu. Claramente o diz São João: "[...] quod (i.e. mysticum et secretissimum) nemo scit, nisi qui accipit" (Apc 2, 17). Em linguagem análoga, já se expressara Plotino: "Aquele que o viu (mergulhando na intimidade do Uno), sabe o que eu digo" (Enéadas, VI, 9,9).

49 LIMA VAZ, SJ, Henrique C. de. Antropologia Filosófica. São Paulo: Edições Loyola, 1991. v. 1, p. 288 , nota 175 .

50 Cf. Historisches Wörterbuch der Philosophie. Band 2, col. 446.

51 Eis um texto de Boécio: "Idcirco quoniam esse eorum a bona voluntate defluxit". (In: Historisches Wörterbuch der Philosophie, Band 2, col. 447). 
Pseudo-Dionísio (Dionísio Areopagita) praticamente só emprega o termo emanação (ékbasis), quando fala em Deus criador. O verbo ktízein raramente ocorre. No Pseudo-Dionísio, há de abeberar-se toda a mística medieval. Temos, depois, João Eriúgena, mediador da teologia oriental para o medievo latino, por sua tradução das obras do Pseudo-Dionísio. Dessarte, abriu à Escolástica as portas para a entrada do neoplatonismo. Deus, segundo Eriúgena, é o Pai das luzes ou a fonte eterna e perene da torrente de luz que se difunde, à maneira de uma cascata, através de todos os degraus hierárquicos dos seres, até chegar às criaturas inferiores e mais afastadas de Deus. ${ }^{52}$

Igualmente Santo Tomás interpreta a emanação como criação: "Não devemos considerar somente a emanação de qualquer ser particular, de um agente particular, mas também o da totalidade dos seres, da causa universal, que é Deus: e é a esta emanação que designamos com o nome de criação" ${ }^{53} \mathrm{O}$ mundo das criaturas é, pois, explicatio da essência divina. Como em Plotino, no Doutor Angélico o mundo criado participa (metéxein), é uma imagem de Deus.

Da mesma forma, em Mestre Eckhart deparamos expressões que indicam emanação. $^{54}$

Inegavelmente, o influxo de Plotino se refletiu em Nicolau de Cusa, na obra De docta ignorantia. Para ele, Deus (Uno) é a complicatio de todas as coisas; o universo criado representa a explicatio.

Também Leibniz retoma a noção de emanacionismo, com sentido de criação. ${ }^{55}$

Nenhum dos personagnes citados se inclui no rol dos panteístas, conquanto muitas vezes sejam qualificados como tais.

Diversa é a concepção de Hegel. No processo dialético, a partir do Uno (Absoluto), este se funde e identifica com o processo vivo da Natureza. O Absolulo é o processo. Estamos, pois, diante de verdadeiro panteísmo.

Assim vemos que Deus ou Uno, como criador (emanante) perpassa a História da Filosofia. Em Plotino, pela primeira vez na evolução do pensamento grego, a Filosofia adquire uma modalidade essencialmente teológica, com amplas ressonâncias nas épocas seguintes. ${ }^{56}$ Em Plotino, mais que em Platão, o interesse volta-se para as realidades transcendentes, com "fuga" do mundo sensivel.

3.2 - Passemos à influencia de Plotino sobre a mística, apontando os tópicos essenciais.

Podemos dizer que Dionísio Areopagita representa o grande transmissor do sentido místico para o Ocidente. Em sua Teologia mística, utiliza termos típicos de Plotino: abandonar todas as coisas (pánta aphelôn). ${ }^{57}$ Propõe três degraus para chegar à união com Deus: a purificação sensivel que consiste na liberação da matéria;

52 Cf. FRAIIE/URDANOZ. Historia de la Filosofia. Madrid: BAC, 1986. v. II (II), p. 327.

53 S. Theol. I, q. 45, a I, 3.

54 Escreveu Eckhart: "Superiora naturaliter se communicant et transfundunt se totis suis inferioribus" (In: Historisches Wörterbuch..., Band 2, col. 447).

55 As Mônadas, segundo Leibniz, resultam "par des fulgurations continuelles de la divinité de moment à moment". $\mathrm{E}$ ainda: "Patet autem $\mathrm{ab}$ hac fonte $(=\mathrm{Deo})$ res existentes continue promanare". (In: Historisches Wörterbuch..., Band 2, col. 448).

56 Cf. FRAIIE/URDANOZ. Historia de la Filosofia. 4. ed. Madrid: BAC, 1976. V. I, p. 9.

57 PG 3, 999. 
a iluminação, mediante a qual a alma entra em contato com Deus; finalmente, a união santificadora que constitui a perfeição da alma, em que ela sai da obscuridade e se une plenamente por amor ao inefável.

Em Santo Agostinho, herdeiro de Plotino, a união mística acha-se descrita na reflexão por ele feita com Mônica, sua mãe, em Óstia. ${ }^{58}$

Vêm a seguir os grandes místicos medievais, com Hugo de São Vítor, São Bernardo, São Boaventura, sem falar de Eckhart, Tauler, Suso, Ruisbróquio e outros. Em não poucos casos, o movimento místico, que também atingiu os universitários, representou uma reação ao nímio intelectualismo no ensino e ao nominalismo. ${ }^{59}$

Na Renascença, atavés da tradução das Enéadas por Marsílio Ficino, o pensamento plotiniano foi considerado como expressão de uma tradição antiqüíssima, com raízes órficas. Deu-se acento à espiritualidade teológica do universo e à afinidade entre a estrutura humana (o homem como microcosmo) e a estrutura cósmica. Ao mesmo passo, foi ressaltado o belo como revelação sensivel de uma ordem metafísica.

Na idade romântica, verificou-se um significativo renascimento do plotinismo. Os românticos não apenas se voltaram ao culto da interioridade, mas ao supra-racional e suprainteligível. Destacam-se Novalis e Schelling. ${ }^{60}$ Ademais, ao mecanicismo determinístico eles opuseram a essência da vida e do ser como mistério. Sublinharam o valor e a função imprescindivel da intuição e do sentimento contra 0 intelectualismo e o racionalismo.

Hoje, no século XX, o pensamento plotiniano é objeto de profundo estudo, especialmente na Europa, e inspira a especulação filosófica. Cito apenas dois expoentes nesse campo: Werner Beierwaltes, com sua obra Pensare l'Uno, e KarlHeinz Volkmann-Schluck, famoso por seu estudo intitulado Plotin als Interpret der Ontologie Platos. O que se percebe, também em outros autores, é a defesa dos direitos do espirito contra o materialismo; do homem interior contra a dispersão do mundo da técnica; a colocação de fronteiras à razão, que se arroga o direito de uma interpretação total da vida, sem adivinhar, nos signos do universo, os indícios de uma Unidade incompreensivel, superior, transcendente.

As grandes idéias dos homens geniais nunca morrem. Entre eles, revela-se o pagão Plotino, como acabamos de ver.

58 Confissões, Livio IX, cap. 10.

"O nominalismo havia criado um clima propício para os místicos, porque, importa recordá-lo, ensinava que a relação entre o homem e Deus apenas podia dar-se pela fé e não pela razão. Logo, somente por exercícios espirituais, o homem lograria entrar em contato com o divino, em profundo amor contemplativo" (UL.TMANN, Reinholdo Aloysio. A Universidade: das origens à Renascença. São Leopoldo: Editora UNISINOS, 1994, p. 185). te, não sendo, pois, algo independente e singular. (Eignes)". (In: Historisches Wörterbuch..., Band 2, col. 448). 